\title{
PANCREATICO-BRONCHIAL FISTULAE
}

\author{
A. P. Dignan, M.B.E., M.B., F.R.C.S. (I) \\ Lt. Col. R.A.M.C., Late Consultant Surgeon, British Military Hospital, Singapore.
}

Pancreatic fistula is not an uncommon condition. It usually presents externally at the site of surgical wounds following operations on the stomach, biliary tract, pancreas, left kidney and spleen. It also results from marsupialisation of false pancreatic cysts, and drainage of pancreatic abscesses. It may follow exploratory operations for trauma or inflammation of the pancreas. Desmond (1962) however states that the incidence of external fistula due to acute pancreatitis is considerably diminished today since the policy of conservative treatment has been established. Even when the routine policy was surgery, the occurrence of fistulæ was slight, unless the pancreatic fascia was incised in many places.

Its formation after marsupialisation is less frequent nowadays, because of the improved results obtained from internal drainage of the cyst into a loop of bowel.

The majority of these fistulæ close spontaneously in due course (Borgstrom, 1961). Hunt (1954) estimated that $80 \%$ of them heal without further surgical intervention.

The development of a bronchial fistula, in conjunction with an external fistula, is a very rare condition, according to its incidence recorded in the literature.

\section{Literature}

Four cases have so far been reported (Hunt, 1954 two cases; Sease, 1956; and Ruffo, Pironti and Massa, 1960). One of Hunt's cases followed trauma to the pancreas and the remaining three, acute pancreatitis.

Rosato and Mackie (1963) in a study of 15 years hospital experience of pancreatic cysts and pseudo-cysts quote a follow up case, in a series of 20 patients, which developed an empyema after a cysto-jejunostomy. Post-operatively, a pancreatic abscess had dissected a fistulous tract into the left pleural cavity.

Keeley and Campbell (1960) in their search in the literature for a previously recorded instance of duodeno-bronchial fistula, found a variety of abdominothoracic fistulous communications reported. Broncho-pleuro-peritoneal fistula presented after gastrectomy and appendicectomy (Gullickson and Smith, 1956). Adams (1955) reported 4 patients with bronchobiliary fistula. A pyogenic subphrenic abscess had ruptured into the pericardium in one case, (Meyer, 1949). A perinephrobronchial (Neilsen, Dick and Maddock, 1950), lumbobronchial (Ribeiro, 1939) and a gastrobronchial fistula (Urizza and Gama, 1954)
had also been recorded.

- Ochsner and De Bakey (1938) in their review $\vec{\circ}$ of 3,608 patients with subdiaphragmatic abscessesfound that $10.5 \%$ had developed bronchopleural $\vec{\omega}$ fistulæ. Although 146 of these cases had origin-o ated from pancreatic lesions, unfortunately noo reference is made of the incidence of pancreatico 3 . bronchial fistulæ. - Berens, Gray and Dockerty (1953) have recorded a series of 154 similar cases; one of which only was secondary to a pancreatic condition, and state that $11 \%$ developed $a$ bronchial fistulæ. Hochberg (1938) reports $1111^{\circ}$ subphrenic abscesses with the thoracic compli-o cation rate being $4.7 \%$. None of these fistula? were pancreatico-bronchial in character.

Fishbein, Murphy and Welder (1962) reviewedo 155 cases of clinically proven pancreatitis in order to determine the incidence of concurrent acute chest radiological changes. 22 patients $(14.28)$ were noted to have radiological findings of pleufif effusion, pleural reaction, plate-like atelectasis basilar infiltrates. Nine of these were in the lefe chest, ten were in the right and three bilaterals No mention was made in this series of a lunge abscess or bronchial fistula.

In the following report, a further case oह pancreatico-bronchial fistula, complicating acute pancreatitis, is described.

\section{Case Report}

A Royal Naval Yeoman aged 36 years wå admitted to the British Military Hospital, Singapore on 31st May, 1961 with a seven-day history of abdominal pain, vomiting, diarrhœa and generał malaise. His symptoms had increased in severity during the 24 hours previous to admission. He was very shocked and presented as an acute abdominal emergency. After resuscitation with fluid therapy an $\$$ other measures, laparotomy was performed through an upper right paramedian incision. Acute hæmoro rhagic pancreatitis was revealed. The abdomen was. closed with a drain placed down to the pancreas After an initial stormy period of post-operative progress, his condition appeared to have settled on the 7 th June (7th post-operative day). However, fever ands tachycardia soon returned. On 14th June a mass was palpable in the left hypochondrium, but as he general condition was satisfactory, observation the progress of the swelling was decided upon. the 29th June he had increasing severe pain in the left shoulder and neck. He became dyspnœic and his general condition deteriorated with a rising pulse rate and increasing pyrexia. A pancreatic pseudo cyst was marsupialised through a left subcostal ing 


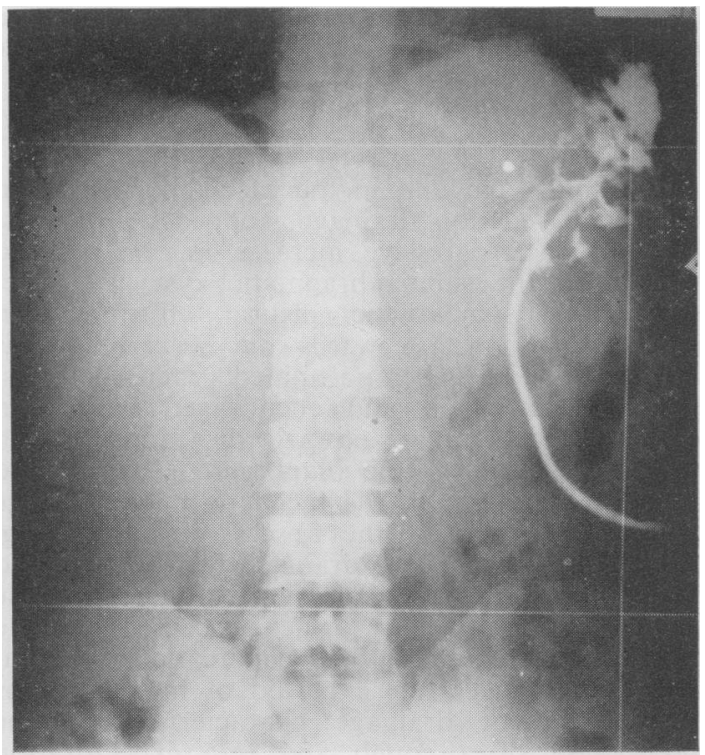

(a)

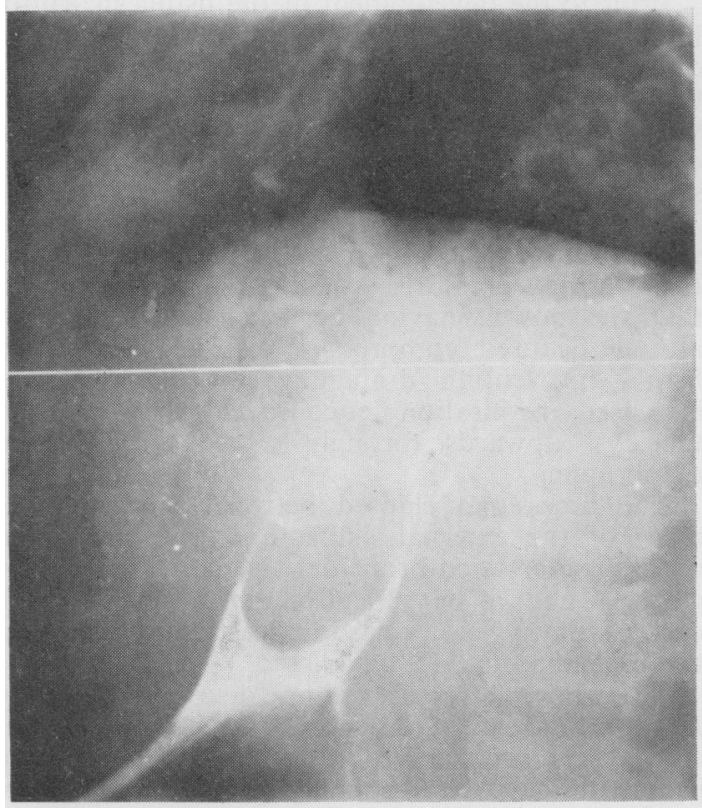

(b)

Fig. 1.-(a) Sinogram P. A. view showing the fistulous tract traversing the diaphragm.

(b) Lateral view of sinogram in Fig. 1 (a).

cision and a wide rubber tube inserted into its cavity. His symptoms were soon completely relieved.

Continuous low-pressure suction was applied by an electrical suction machine to the drainage tube on the 6th July. $960 \mathrm{ml}$. of fluid was drained in 24 hours on 7 th July. Unfortunately the machine broke down on the following evening, necessitating resorting to open drainage. There was a rise in his

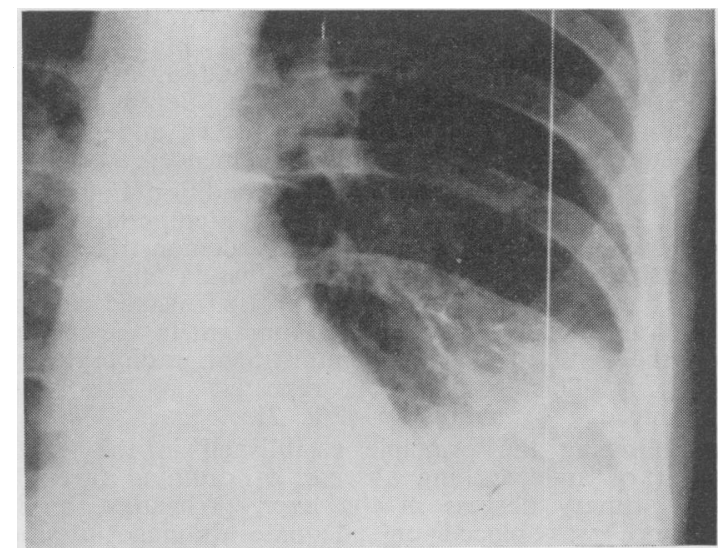

(a)

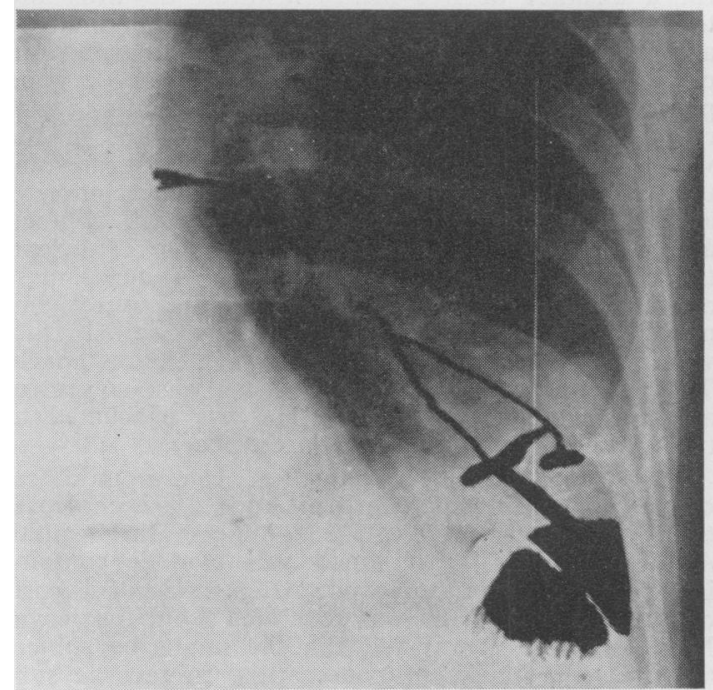

(b)

FIG. 2.-(a) Radiograph of chest showing bronchogram produced by injection of lipiodol into the external abdominal fistula.

(b) Diagrammatic representation of bronchogram seen in Fig. 2 (a).

evening temperature on the 9th and 10th July. His general condition had deteriorated on the 11th July, with a high pulse rate persisting throughout the day. $\mathrm{He}$ also had diarrhœa.

Continuous suction was re-established on 12 th July with immediate improvement in his general condition. The diarrhoea ceased and the pulse rate and temperature dropped. Chest X-ray showed that he had a left basal effusion and that the diaphragm on that side was raised. During the next two days his general condition was maintained but he had a cough productive of sputum.

On the 15th July the suction pump again stopped. On the 17th July his condition seriously deteriorated. $\mathrm{He}^{-}$was very distressed with a persistent productive cough throughout the day. His pulse rate rose to 
140 per minute and his temperature to $103^{\circ}$. X-ray examination revealed a left basal lung abscess. Continuous suction was re-established using a long polythene tube placed well into the depths of the wound. Postural drainage was instituted and penicillin and streptomycin therapy commenced.

On the 18th July his general condition improved with decrease of pulse rate and temperature. A pancreatico-bronchial fistula was demonstrated by injecting methylene blue into the fistula and observing blue sputum. Lipiodol was also injected and a fistulous tract traversing the diaphragm in the region of the left dome was demonstrated radiologically (Fig. 1). This investigation, repeated on 28th July, produced a bronchogram (Fig. 2).

Following the principle established in the treatment of amobic lung abscess, of draining through the primary abscess in the liver, (Wheatley, 1958) reliance was placed on adequate drainage of the abdominal fistula.' The fistulous tract was dilated using a Clutton bougie size $24 / 28$. It passed easily for a distance of five inches inwards, upwards and to the left. Continuous suction was well maintained and bouginage of the fistulous tract was carried out on alternate days. The patient thereafter made good progress, his fever subsided, the cough and expectoration diminished and there was reduction in the volume of fluid drained. On 21 st September resolution of the lung abscess was radiologically complete, although drainage from the fistula was still appreciable in quantity (at least $90 \mathrm{ml}$./day). On 23rd Sept. the tract of the fistula was explored. A dense mass of fibrous tissue made removal of its source impossible. The extremely robust thick walled tract was anastomosed to the posterior wall of the stomach. The patient's post-operative recovery was uneventful and the wound healed well. He was evacuated to the United Kingdom on 29th October.

Following further investigation for a mild recurrent attack of pancreatitis in April, 1962, cholecystectomy was performed in the Hammersmith Hospital. A large chronically inflamed gall bladder containing two stones was removed. After uneventful postoperative recovery, he was invalided from the Royal Navy, because it was felt that he might be subject to recurrent attacks of pancreatitis. In fact he subsequently had recurrent episodes of upper abdominal pain and vomiting.

Mr. G. C. Dorling in a personal communication stated that $\mathrm{Ba}$ meal X-ray, carried out on 11th September, 1963 , indicated that there were probably several large cysts in the pancreas, causing extensive defects on the stomach, and that some change in the mucous membrane of the stomach, at the side of the anastomosis, was present, causing delay in passage of the barium, from the proximal to distal end of the stomach. Chest X-ray showed evidence of adhesions at left base causing some elevation of the diaphragm, but no evidence of subphrenic abscess. He performed a laparotomy on the 11th October, 1963. The liver and stomach were adherent to the abdominal wall. There was no subphrenic abscess and no cyst present in the pancreas. Palpation of the stomach revealed an ulcer in the posterior wall of its distal half, which may have been the site of the anastomosis of the fistula. Dense adhesions made it impossible to inspect it, and also to free the lesser curvature sufficiently to allow of a defunctioning gastrojejunostomy being carried out. He performed a posterior antecolic gastrojejunostomy to relieve the obstruction seen in barium meal examination, and to allow any ulcer to heal. The patient made a good rapid post-operative recovery, being discharged home on the 20th October, 1963.

\section{Discussion}

It would seem that in the case reported, when continuous suction drainage stopped on the fir occasion, a progressive increase in size of and tension in the subdiaphragmatic cyst cavity res sulted. A sympathetic pleural effusion the appeared. Soon afterwards the severity of his cough, it could be postulated, increased res? piratory movement and encouraged infiltratio $\vec{b}$ of the abscess in an upward direction through a weak portion of the diaphragm. The second incident of failure in the mechanism of drainags caused extension of the abscess into the lung

Sease's case had free drainage from her wound after the initial exploratory laparotomy, until the 14th post-operative day, when it ceased and the drains were removed. The pancreatico-bronchiad fistula presented after a period of many months of intermittent drainage characterised by the production of a cough and free expectoratiog when drainage ceased.

Prior to the development of the fistula in Ruffo Pironti and Massa's case, there had been adequats drainage from the abdominal fistula for about two months, of about $1500 \mathrm{ml}$. daily. Subsequently over a period of a few days, the vollome of fluid drained became reduced to $100 \mathrm{ml}$. Ind soon drainage ceased completely.

In Hunt's two cases, the complication occurgeg soon after they had been evacuated from the $F a+$ East in non-pressurised aircraft. He postulated that the bowel, having been distended by high altitude, caused compression of the thin-walleg fistula, preventing drainage from it, and that increased respiration encouraged discharge of the cyst upwards through a weak site in the diaphragm.

The times that elapsed between the establish: ment of the external fistula and the occurrence of the pancreatico-bronchial fistula were: Hunt cases 91 and 74 days; Ruffo, Pironti and Massa? case 65 days; Sease's case at least 2 months; and the case reported 18 days.

The thoracic complication developed acutel in all cases except Sease's case. It was charae terised by the cessation of drainage of the pancreatic secretions coinciding with the produc: tion of a cough with free expectoration.

The treatment of the complication consistes simply of dependent abdominal drainage in case 3 of Hunt's, in Sease's case, and also in Ruffe Pironti and Massa's case, although it was como bined with direot thoracotomy drainage of the lung abscess in the latter case. Case 1 of Hunts did not allow of prolonged abdominal drainage because of the steady deterioration in the patiens condition, and more positive surgical interventiog was called for i.e. attempted removal of the source, partial pancreatectomy, which was successful.

\section{(a)}

.


Bouginage of the external portion of the tract in the case reported allowed its lumen to be kept open to facilitate suction to be adequately applied. The bougies were passed without any force in the manner of the "tour de maitre", used in urethral bouginage, approximately every 2 days, over a period of two months, and were responsible for a thick walled, well defined fistulous tube being formed. Lahey and Lenin (1937) have reported a case of external fistula which they treated successfully by first dilating the fistulous tract up to a French No. 22 sound, and then anastomosing the fistula to a loop of jejunum.

\section{Conclusions}

External fistulæ are slow to heal and should be avoided if possible. Internal drainage of a pseudo-cyst is preferable to external if the patient is a good risk and the cyst wall is well developed (Rosato and Mackie, 1963).

It is during the prolonged period after the establishment of an external fistula, while conservative measures are adopted in the hope that it will close spontaneously, that this serious complication may occur. In the recorded cases, it followed the interruption of drainage from the fistulæ.

Intensive care of the abdominal sinus from the point of view of maintaining adequate and persistent drainage is therefore essential. Brilhart and Priestley (1951), in reporting a series of 31 pseudo-cysts treated with incision and drainage with or without marsupialisation, state that, in each of the three cases which recurred, it appeared that the period of drainage had been inadequate. In cases where incision and simple drainage was performed, the average period of drainage of a cyst was two and a half months. When incision and marsupialisation were employed, the average duration of post-operative drainage was three and a third months approximately.

Continuous suction is the most effective way of keeping the cyst cavity empty. Bouginage of the tract may be necessary to maintain an adequate lumen in it. Stern (1930) states that these fistula never become lined with epithelium and repeatedly become blocked.

Radiological visualisation of the fistula and its communication with the cyst may be of value in indicating that more dependent direct drainage of the pancreatic secretions is necessary.

A thoracic complication should be suspected if the patient develops a productive cough coinciding with cessation of drainage from the fistula. A sinogram, chest X-ray examination, examination of the sputum for pancreatic enzymes, and injection of methylene blue into the external fistula are imperative when these symptoms present, and should even be carried out, when only interruption of drainage occurs. The progress of thoracic extension is rapid because of the action of pancreatic enzymes on the congenitally weak portions of the left half of the diaphragm. In pleural effusions associated with pancreatic lesions a high amylase content has been demonstrated on several occasions. (Hammarstein, Honska and Lunes, 1939; Kalser, Roth and Hockus, 1955; and Werner, 1952). In Hunt's two cases the sputum was found to contain enzymes.

The treatment of a pancreatico-bronchial fistula should be directed towards establishing adequate dependent drainage below the diaphragm. If this can be achieved, thoracotomy will not be necessary.

This complication is probably not so rare as the literature would indicate to us. It is possible that more cases occur and are not published or do not become detected. Presumably it could occur in the absence of an external fistula.

\section{Summary}

1. A case of pancreatico-bronchial fistula is presented and discussed in conjunction with four other cases previously reported in the literature. 2. Conclusions are drawn, emphasising the importance of :-

(a) Maintaining adequate continuous suction drainage, while the advent of their spontaneous healing is being awaited, in preventing the development of pancreaticobronchial fistulæ. The use of bouginage of the fistulous tract is mentioned.

(b) Sinogram and chest X-ray examination, being essential to diagnose this complication at an early stage.

(c) The onset of a productive cough with the coincidental cessation of drainage from the abdominal fistula being suggestive of involvement of the lung.

3. The treatment of this serious complication, would appear to be essentially, re-establishment of adequate abdominal drainage of the pancreatic abscess.

I am grateful to the DGAMS and Col. R. L. Marks for permission to publish this paper. I wish to thank Brigadier P. R. Wheatley and Professor L. F. Tinckler for their advice and criticism, and also Colonel R. S. Hunt for his invaluable advice in the treatment of the case reported. Lt. Col. P. Bretlind, RAMC, and Capt. W. J. Johnston, RAMC, helped in the production of the photographs.

\section{REFERENCES}

Adams, H. D. (1955): Pleurobiliary and Bronchobiliary Fistulas, J. thorac. Surg., 30, 255.

Berens, J. J., Gray, H. K. and DOCKerTy, M. B. (1953): Subphrenic Abscess, Surg. Gynec. Obstet., 96, 463.

BoRGSTROM, S. (1961): External Pancreatic Fistula, ibid, 112, 639.

Brilhart, K. B. and Priestley, J. T. (1951): Pseudocysts of the Pancreas, Amer. J. Surg., 81, 151.

Desmond, A. M. (1962): Pancreatic and Duodenal Fistulæ, Proc. roy. Soc. Med., 55, 202.

DoRling, G. C. (1963): Personal Communications.

Fishbein, R. H., MURPHY, G. P., Wilder, R. J., (1962): The Pleuro-Pulmonary Manifestations of Pancreatitis, Dis. Chest, 41, 392. 
Gullickson, M. J., and SMith, G. R. (1956): Immediate Treatment of Bronchopleural-Peritoneal Fistula, J. thorac. Surg. 31, 324.

HAMmarstein, J. F., HonSKa, W. L. JR., and Lunes, V. (1959): Pleural Fluid Amylase in Pancreatitis and Other Diseases, Amer. Rev. Tuberc., 79, 606.

HochberG, L. A. (1938): Subphrenic Abscess: Review of 111 Cases and a Resumé of the Subject, Arch. Surg., 36, 111.

HuNT, R. S. (1954): Pancreatico-Bronchial Fistula, Brit. J. Surg., 41, 170.

KAlSER, M. H., Roth, J. L. A., and BockuS, H. L. (1955): Relapsing Pancreatitis with Pseudocysts of the Pancreas and Enzyme Containing Pleural Effusion, Gastreoenterology, 28, 842.

Keeley, J. L., Campbell, T. A., (1960): DuodenoBronchial Fistula with a Summary of AbdominoThoracic Fistula, J. thor. Cardiovasc. Surg., 39, 538.

LAHEY, F. H. and LenIN, R. (1937): Cure of Pancreatic Fistula by Pancreatico-Jejunostomy, Report of a Case with Review of the Literature, Surg. Gynec. Obstet., 64, 79.

MeYer, N. C. (1949): Rupture of a Subphrenic Abscess Into the Pericardium, Ann. Surg., 129, 148.

NeIlsen, A. M., Dick, G. F. and MADDOCK, W. G. (1950): Chronic Perinephric Abscess With Perine-
phro-Bronchial Fistula and Psoas Abscess, J. Urol 63, 433.

OCHSNER, A., and DE BAKEY, M. (1938): Subphreniळ Abscess: Collective Review and Analysis of 3,608 Collected and Personal Cases, Internat. Abstr. Surg.:66, 426, in Surg. Gynec. Obstet., May, 1938.

Ribeiro, E. B. (1939): Sobre um Case Singular Delithiase Renal, Ann. paulist. med. cir., 38, 2150

Rosato, F. E., and MacKIE, J. A. (1963): Pancreati Cysts and Pseudocysts. A Study of 15 Years Hos pital Experience, Arch. Surg., 86, 551.

Ruffo, A., Pironti, L., Massa, G. (1960): Pang creatico-Pulmonary Fistula. Description of a Case, Minerva med., 51, 2537.

SEASE, C. I. (1956): Bronchial-Pancreatic Fistula. A Case Report, Virginia med. Mth., 83, 11.

Stern, E. L. (1930): Traumatic Injuries to the Pan? creas, Amer. J. Surg., 8, 58.

Urizza, J. L., and Ramierez Gama, J. (1954): Fistulæ. Gastro-bronquial Consecutiva a Hernia Diafrags matic, no Traumatica, Rev. mex. Tubert., 15, 208

Wheatley, P. R. (1958): Basic Surgery, p. $189 \mathrm{~W}$ London: H. K. Lewis.

WERNER, H. (1952): Zbl. inn. Med., 63, 577. 